\title{
Combining evidence presented simultaneously to the eye and the ear: A comparison of some predictive models
}

\author{
A. CRAIG and W. P. COLQUHOUN \\ Medical Research Council Perceptual and Cognitive Performance Unit \\ Laboratory of Experimental Psychology, University of Sussex, Brighton, Sussex, England \\ and \\ D. W. J. CORCORAN \\ Department of Psychology, University of Glasgow, Glasgow, Scotland
}

\begin{abstract}
Data from a sustained monitoring experiment involving auditory, visual and combined audio-visual signal recognition were used to assess the predictive validity of five models of bisensory information processing. Satisfactory predictions of the dual-mode performance levels were made only by two models, neither of which assumes that the auditory and visual systems operate independently, and correlations which attest to this nonindependence are presented. One of these models explicitly assumes that the two systems are associated so that their judgments tend to coincide; the other assumes that the visual system "alerts" the auditory system to the presence of a signal. Both models accurately predict the levels of $d^{\prime}$ and $\beta$ in the dual-mode condition, and the "alerting" one also accounts for the observed reduction in response latencies.
\end{abstract}

The question of whether information arriving simultaneously over two modalities can be combined within the nervous system to result in a level of performance of greater efficiency than that derived from presentation over a single mode has been raised in several experimental contexts. In some studies, the focus has been upon reaction time (RT) measures (e.g., Bernstein, Rose, \& Ashe, 1970; Hershenson, 1962; Morrell, 1968; Raab, 1961; Todd, 1912), in others, upon the perception of written and auditory verbal materials (e.g., Dougherty, Jones, \& Engel, 1971; Pollack, 1964; Tulving, Mandler, \& Baumal, 1964); and one study has examined the recognition processes in nonverbal materials (Corcoran \& Weening, 1969). Of particular relevance to the present investigation are those studies in which auditory, visual, and dual mode (audio-visual) information has been presented in a detection or vigilance task situation, and the signals have been difficult to discriminate (e.g., Baker, Ware, \& Sipowicz, 1962; Brown \& Hopkins, 1967; Buckner \& McGrath, 1963; Colquhoun, 1975; Osborn, Sheldon, \& Baker, 1963; Tyler, Waag, \& Halcomb, 1972; Loveless, Note 1). Loveless, Brebner, and Hamilton (1970) have reviewed the literature in all the areas mentioned above. Colquhoun (1975)

This work has been carried out with the support of the Procurement Executive, U. K. Ministry of Defence. The authors would like to thank Mr. R. S. Edwards, of the Medical Research Council Applied Psychology Unit, who carried out the testing. summarizes much of the evidence from detection or monitoring studies.

There is little question but that a generalized conclusion can be drawn which covers nearly all the audio-visual detection studies: performance efficiency in at least some task parameters is improved relative to the better of the unimodal conditions. However, the question of how such improvement comes about is still a matter of speculation (Nickerson, 1973).

Four broad classes of theory have been examined previously, and these, along with a fifth model which is introduced here, are dealt with in this paper.

\section{Model 1}

The earliest (and perhaps the simplest) theory assumes that the auditory and visual systems are independent and that each produces a categorical decision based upon the sensory evidence. These categorical decisions are then relayed to a second decision-making stage, where the operating rule is assumed to be that whenever either or both decisions indicate the presence of a signal the observer reports that a signal is present. This model, referred to as "statistical summation" (Loveless et al., 1970) is described by the equation

$$
p_{a v}=p_{a} p_{v}+p_{a}\left(1-p_{v}\right)+p_{v}\left(1-p_{a}\right),
$$

which reduces to 


$$
p_{a v}=p_{a}+p_{v}-p_{a} p_{v},
$$

where $p_{a v}$ is the probability of detecting a signal given simultaneous auditory and visual inputs and $p_{a}$ and $p_{v}$ refer to the probabilities of detection with only auditory or visual displays, respectively. This model consistently overpredicts audio-visual detection performance. ${ }^{1}$

\section{Model 2}

A related theory (Corcoran \& Weening, 1969) assumes, like the statistical summation model, that the auditory and visual systems make independent decisions, but postulates that a signal is not always reported by the subject when one or both modalities indicate its presence. Although signals are always reported when both modalities agree, when they are in conflict signals are reported only on a proportion of the occasions. This proportion is assumed to be related to the strength of the precategorical (analog) evidence upon which each modality bases its decision. . The predictions of this model (excepting the refinement that the observer may elect to ignore information from a source whose reliability is not sufficiently high) can be estimated from the descriptive equation

$$
\begin{aligned}
p_{a v}= & p_{a} p_{v}+p_{a}\left(1-p_{v}\right) \times \frac{p_{a}}{p_{a}+\left(1-p_{v}\right)} \\
& +p_{v}\left(1-p_{a}\right) \times \frac{p_{v}}{p_{v}+\left(1-p_{a}\right)}
\end{aligned}
$$

This theory was shown to fit certain detection data (Corcoran \& Weening, 1969) in addition to the recognition data for which it was primarily designed.

\section{Model 3}

A third theory assumes that the outputs from independent auditory and visual sources are qualitatively the same at the internal, analog level, and can therefore be integrated. Thus, seeing and hearing is considered equivalent to a "double look" (Green \& Swets, 1966) or to a "double listen." It is hypothesized, in this model, that a single categorical decision is made on the basis of the integrated information, rather than two categorical decisions which subsequently have to be combined statistically. This is clearly an efficient way for the system to work, but in most cases this model proves too efficient as a description of the real system. Although the integration model is somewhat favored by Loveless et al. (1970), the great majority of existing data are overestimated by the appropriate equation

$$
\left(d^{\prime}{ }_{a v}\right)^{2}=\left(d^{\prime} a\right)^{2}+\left(d^{\prime}{ }_{v}\right)^{2},
$$

where $\mathrm{d}^{\prime}{ }_{\mathrm{av}}$ is the index of signal detectability (Green \& Swets, 1966) in the dual-mode condition, and $\mathrm{d}^{\prime}{ }_{\mathrm{a}}$ and $\mathrm{d}^{\prime}{ }_{\mathrm{v}}$ are the corresponding indices with only auditory or visual displays, respectively. The overestimation will be obvious in the data from the present experiment. Bernstein (1970) also discusses and rejects the theory as an adequate description of audiovisual $R T$ data.

\section{Model 4}

A fourth theory, favored by Bernstein et al. (1970), Kohfeld (1969), and Nickerson (1973) is a cueing theory, in which one modality serves to alert the other to the presence of a possible signal. Detection (or, in RT studies, the initiation of a motor response) is then based upon an analysis of the cued modality; the sensitivity of this (cued) modality is uninfluenced by alerting, which is assumed to effect a change in the response criterion only. The validity of such a cueing model has received support in a study by Davenport (1969), using auditory and cutaneous signals (see also Howarth \& Treisman, 1958; Treisman, 1964).

The earlier statements of this model concentrated on the facilitating effects (i.e., reduced response latency) of the presence of an accessory extramodal stimulus. Nickerson (1973) argues that such a stimulus serves to increase the two components of expectancy, (a) the preparedness to respond as observed in the reduced latencies, and (b) the propensity for response evocation reflected in the occurrence of false alarms on those catch trials when the imperative stimulus is not presented. Clearly, these "accessory stimulus" studies, in which the alerting stimulus is always easily discernible, are only of indirect relevance for the problem of bimodal detection where the alerting stimulus is, by definition, not easy to detect. Nevertheless, certain parallels can be drawn enabling predictive statements to be made about the latter situation. It should be made clear to the reader, however, that the following version of such a cueing model applicable to data like those in the present experiment, is the surmise of the authors; invalidation of this particular version by the experimental data will not necessarily reflect on the more general validity of the alerting model in RT studies.

It is assumed that one modality consistently functions to cue the other. When the alerting modality "decides" that a signal has been presented, this increases the expectancy in the cued modality, thereby causing a reduction both in the latter's criterion to respond and in the latency of the "detect" response (when given). On the other hand, when the alerting modality decides that a signal has not been given, the argument, by symmetry of effect, is that the observe happens: the response criterion of the cued modality is increased so that the detect response is less likely to be given and, if the response does occur, the latency. is increased. These effects are, of course, relative to the latency and criterion for the 
cued modality when it alone is involved. In the extreme case, where the cueing effect is sufficiently strong, the criterion of the cued modality will match that of the alerting modality.

By implication, then, the predictions of this cueing model are that the dual-mode criterion $(\beta)$ is shifted (relative to that of the cued modality) in the direction of the criterion of the alerting modality, while the efficiency $\left(d^{\prime}\right)$ remains unaltered. It is anticipated that the effect of the alerting modality on response latencies will reflect the relative levels of the response criteria of the alerting and cued modalities. Facilitation (reduced latencies in the dual-mode condition) will result if the alerting modality has a lower criterion than the cued modality.

The model described states that the dual-mode efficiency is determined by the efficiency of the cued modality; that the alerting modality serves only to influence the response bias. Since previous studies have shown that dual-mode efficiency is at least as good as the better of the individual modes, and invariably superior to the poorer mode (Colquhoun, 1975; Dougherty et al., 1971; Fidell, 1970; Loveless et al., 1970), the suggestion for the present model is that the input to the more efficient modality serves as equivalent to the "imperative stimulus" of the RT studies mentioned earlier, while the less efficient modality performs the alerting function.

Compliance with this formulation of a cueing model will require, as evidence of a cueing effect, that the following obtain: if the auditory mode is the more efficient,

$$
\left|\beta_{\mathrm{av}}-\beta_{\mathrm{v}}\right|<\left|\beta_{\mathrm{av}}-\beta_{\mathrm{a}}\right| \text { when } \beta_{\mathrm{a}} \neq \beta_{\mathrm{v}}
$$

and

$$
\mathrm{RT}_{\mathrm{av}}<\mathrm{RT}_{\mathrm{a}} \text {, when } \beta_{\mathrm{a}}>\beta_{\mathrm{v}} \text {, }
$$

while

$$
d^{\prime}{ }_{a v}=d^{\prime}{ }_{a} \text { and } d^{\prime}{ }_{a v} \neq d^{\prime}{ }_{v} \text {, when } d^{\prime}{ }_{a} \neq d^{\prime}{ }_{v} \text {. }
$$

If the visual mode is the better, then the subscripts $\mathrm{a}, \mathrm{v}$ will be correspondingly interchanged.

\section{Model 5}

A fifth, and final, theory considered here assumes that in the dual-mode condition there is an inputoutput function which can be described as the combination of two correlated variables, $\mathrm{p}_{\mathrm{a}}$ and $\mathrm{p}_{\mathrm{v}}$, whose values are as defined by the unimodal conditions.

The assumption made in the earlier models which have been discussed, that the two sensory systems (auditory and visual) are independent, seems un- justified for several reasons. In the first place, there is a noticeable tendency for good visual monitors to be good auditory monitors also, as is indicated, for example, by the high positive correlations obtained by Colquhoun (1975) between the performance of a group of subjects monitoring a visual display and the performance of the same subjects monitoring an auditory display. From such evidence, it seems probable that the auditory and the visual systems will not yield data which are statistically independent, and this would be a sufficient condition for the present model. A second reason for doubtifig the earlier assumption of independence is that if a central decision-maker is involved in the dual-mode situation, then its common bias could account for an association between the systems. Finally, one might argue that the overestimations in the predictions of the statistical summation model and the integration model are indicative of nonindependence. [The presence of correlation at this analogue level has been considered by Eijkman and Vendrik (1965) and by Fidell (1970), among others.] Thus, for whichever reason, the key assumption of this fifth model is that in the dual-mode condition the evidence from the auditory system is correlated with that from the visual system.

The predictive equation, which also describes the model is

$$
\left.p_{a v}=p_{a}+p_{v}-p_{a} p_{v}-\phi \sqrt{p_{a}\left(1-p_{a}\right) p_{v}\left(1-p_{v}\right.}\right)
$$

where $\phi$ is the correlation coefficient indexing the association between the auditory and visual inputs. In accordance with the statements just made, it is assumed that $\phi$ is a random variable, restricted to the range $0-+1$, with an expected (i.e., mean) value of 0.5 . Clearly, this equation resembles that for the statistical summation model, differing only in the final term on the right-hand side. Setting $\phi=0$ in Equation 5 would lead directly to Equation 1. Both models are in agreement that a signal will be reported when either or both modalities indicate its presence; they differ in the extent to which they predict coincidence rather than conflict between the decisions of the two modalities. For purposes of identification, this fifth model will be referred to as the "phi" model.

The present experiment seeks to test the five theories described above against data obtained under auditory (A), visual (V), and audio-visual (AV) conditions. The reader is cautioned, however, that since the situation was designed as a detection task (in order that the values of the SDT parameters could be assessed), the signals were, of necessity, difficult to discriminate. Because of this, the obtained response latencies to these signals are 
considerably greater than standard RT measures, and may not, therefore, be directly comparable to the latter.

\section{METHOD}

\section{Task}

The auditory (A) version of the task used was very similar to that described by Colquhoun and Baddeley (1967), who have demonstrated typical "vigilance" effects in its performance. The subject monitored, over headphones, a series of $950-\mathrm{Hz}$ tones, one of which occurred every $3 \mathrm{sec}$ and remained on for a duration of (normally) $0.6 \mathrm{sec}$. He was instructed to report a "signal" tone (a tone of $0.7 \mathrm{sec}$ duration) whenever he suspected that one had been presented. His report was made by pressing one of three keys according to his subjective rating of confidence in his decision that a signal had indeed occurred. The keys connoted (from left to right) "uncertain," "fairly sure," and "certain" categories of decision and were mounted $2.5 \mathrm{~cm}$ apart on a small console resting on a platform at table height. This platform also acted as an armrest for the subject, who was comfortably seated facing the console, the distance of the latter from the front of the platform being individually adjusted for ready manipulation of the keys by the subject's preferred hand. The tones were presented at a level of approximately $80 \mathrm{dBa}$ against a continuous background of white noise of approximately $60 \mathrm{dBa}$, which served to mask extraneous sounds from the apparatus.

For the visual (V) version of the task, the tones were replaced by illuminations of a circular aperture, $1.5 \mathrm{~cm}$ in diameter, cut in a small matt-surfaced plate inclined at an angle of $45^{\circ}$, and positioned such that the center of the aperture was $3.5 \mathrm{~cm}$ above the middle of the three response keys and $7.5 \mathrm{~cm}$ behind it. The aperture was covered with $3-\mathrm{mm}$ sandblasted Perspex to provide uniform illumination of its entire area, and was lit from behind by a 12-V amber-colored neon lamp (Phillips Type GL $42 \mathrm{~W}$ ). In relation to the level of the ambient lighting in the test room, this produced a stimulus that, while readily visible, avoided the induction of afterimages, and minimized glare. The subject wore headphones, as in the auditory case, and the background masking noise was continuously present, as before. The durations of the standard and signal illuminations were identical with those of the corresponding tones in the A condition.

In the audio-visual (AV) condition, the auditory and visual versions of the task as described above were presented together, the tones and illuminations occurring simultaneously.

\section{Subjects and Design}

The subjects were 18 enlisted men with an age range of 18-30 years, who volunteered for the experiment. They were tested in groups of 3 , each subject having his own identical display and response equipment, as described above. Following initial instruction in the use of the response keys and the necessity to report signals as quickly as possible, the subjects were given approximately $2 \mathrm{~h}$ practice in each of the three versions of the task. In the early stages of this practice, the trial blocks were short (circa $5 \mathrm{~min}$ ), signal probability was high, and immediate feedback of performance efficiency was provided visually by means of a green lamp placed near the response keys, which flashed briefly $2 \mathrm{sec}$ after a "signal" stimulus had been presented. In the later stages of practice, the trial blocks were of a length similar to that used for the test sessions proper, signal probability was equivalent to that actually employed in these sessions $(0.05)$, and feedback was reduced to posttrial block quotation of the achieved detection rate (always expressed as a percentage in order to prevent subjects' acquiring knowledge of the actual number of signals presented).

On the day following the final practice trial, the subjects commenced a series of 121 -h test sessions, which were held at the rate of two per day at the same times of day (one morning and one afternoon session) for 6 days. Each session was divided into three 20-min periods; one of these periods was held under the $A$ condition, one under the $\mathrm{V}$ condition, and one under the $A V$ condition. There were no breaks between the periods. The subjects met each of the six possible sequences of conditions once in the first six sessions, and once again in the last six. The order of presentation of the sequences differed between groups of subjects in such a way as to balance out any possible effects from this factor, but the particular order assigned to a given group was the same for the first and last six sessions.

Twenty signals were presented to each subject in each $20-\mathrm{min}$ period. The positions of these signals in the stimulus series were determined at random, apart from constraints which ensured (i) that a signal was never presented to more than one of the three subjects at a time and (ii) that the stimulus immediately following a signal was always a standard (nonsignal) stimulus. These constraints minimized the possibility of recorder error resulting from having to $\log$ two responses occurring in quick succession. The subjects were aware of the constraints, and also of the fact that a different sequence of signals and nonsignals was used for each session. All responses, whether correct or not, were recorded, together with response times to signals, measured electronically to an accuracy of $0.01 \mathrm{sec}$. Any response made during the actual presentation of a stimulus was scored as a false alarm, irrespective of whether the previous stimulus had been a signal or not (the subject was warned that this would be the case in order to encourage him to make his responses as rapidly as possible; that this warning achieved its desired effect was, in the event, attested to by the very small number of "delayed" responses actually recorded). Subjects were given no indication of their performance levels until completion of the entire experiment.

It had been anticipated that the provision of the response keys, affording expression of the subjects' confidence levels, would yield data in a form from which receiver operating characteristic (ROC) functions (detection rate as a function of false-alarm rate) could be constructed. These, in turn, would have been used to check on the applicability of the signal detection theory measures (required for tests of the integration and cueing models) to the data (see, for example, Broadbent \& Gregory, 1963). In the event, however, very few commissive errors were made and it was clear that the derived false-alarm rates, when distributed over the three response categories, were not sufficiently reliable to serve the intended purpose. For this reason, the confidence levels were ignored and the data were summed over the response categories prior to calculating the measures which are now defined.

\section{Response Measures}

The following response measures were calculated for each subject for each period of each session:

(1) Percent detection: the number of signals to which a response was made, expressed as a proportion of the 20 signals presented.

(2) Percent fatse alarms: the number of all other responses made, expressed as a proportion of the 380 nonsignal stimuli presented.

(3) Percent correct: the number of correct decisions made (including the decision not to respond) expressed as a proportion of the $\mathbf{4 0 0}$ stimulus presentations given.

(4) Percent "signal" reports: the total number of "signal" reports made (including those classified as false alarms) expressed as a proportion of the 400 stimulus presentations.

(5) $d^{\prime}$ : derived from the tables published by Freeman (1973), using values of $p(\mathrm{H})$ and $p(F A)$ computed as in (1) and (2) above, making the necessary assumption of signal detection theory concerning equality of the "noise" and "signal-plus-noise" variances.

(6) $\beta$ : as for (5) above.

(7) Reaction time $(R T)$ : the mean latency of responses to signals.

It is clear from the description of the experimental protocol 
Table 1

Summary of Overall Findings and Statistical Comparisons

\begin{tabular}{|c|c|c|c|c|c|c|c|c|}
\hline \multirow{2}{*}{\multicolumn{2}{|c|}{$\begin{array}{c}\text { Measure } \\
\text { I }\end{array}$}} & \multicolumn{3}{|c|}{ Mean Scores } & \multicolumn{4}{|c|}{ Statistical (Wilcoxon T) Tests } \\
\hline & & II & III & IV & V & VI & VII & VIII \\
\hline & & $\mathbf{A}$ & V & AV & A vs. V & A vs. AV & V vs, AV & AV vs. A or V \\
\hline $\mathbf{a}$ & Mean Percent Detections & 53.35 & 40.46 & 59.65 & $\begin{array}{l}T=6 \\
p<.01\end{array}$ & $\begin{array}{l}T=8.5 \\
\mathrm{p}<.01\end{array}$ & $\begin{array}{l}\mathrm{T}=2 \\
\mathrm{p}<.01\end{array}$ & $\begin{array}{l}\mathrm{T}=17.5 \\
\mathrm{p}<.01\end{array}$ \\
\hline b & Mean Percent False Alarms & 4.46 & 5.16 & 5.18 & $\begin{array}{l}T=39 \\
p<.01\end{array}$ & $\begin{array}{l}\mathrm{T}=0 \\
\mathrm{p}<.01\end{array}$ & n.s. & $\begin{array}{l}T=0 \\
p<.01\end{array}$ \\
\hline c & Mean Percent Correct & 94.43 & 92.12 & 93.07 & $\begin{array}{l}T=19 \\
p<.01\end{array}$ & n.s. & $\begin{array}{l}T=32.5 \\
p<.05\end{array}$ & $\begin{array}{l}T \neq 32 \\
p \& .02\end{array}$ \\
\hline d & Mean Percent "Signal" & 6.58 & 6.93 & 7.90 & n.s. & $\begin{array}{l}\mathbf{T}=0 \\
\mathrm{p}<.01\end{array}$ & $\begin{array}{l}\mathrm{T}=22 \\
\mathrm{p}<.01\end{array}$ & $\begin{array}{l}T=37 \\
\mathrm{p}<.05\end{array}$ \\
\hline e & Mean $d^{\prime}$ & 1.85 & 1.41 & 1.95 & $\begin{array}{l}T=9 \\
p<.01\end{array}$ & n.s. & $\begin{array}{l}\mathrm{T}=3.5 \\
\mathrm{p}<.01\end{array}$ & n.s. \\
\hline f & Mean $\beta$ & 4.70 & 3.97 & 4.10 & $\begin{array}{l}\mathrm{T}=25 \\
\mathrm{p}<.01\end{array}$ & $\begin{array}{l}\mathrm{T}=4.5 \\
\mathrm{p}<.01\end{array}$ & n.s. & n.s. \\
\hline g & Mean RT in Seconds & .75 & .79 & .72 & n.s. & $\begin{array}{l}T=4 \\
\mathrm{p}<.01\end{array}$ & $\begin{array}{l}\mathrm{T}=15 \\
\mathrm{p}<.01\end{array}$ & n.s. \\
\hline
\end{tabular}

that the conditions under which the task was performed correspond closely to those applying in vigilance experiments, in which withinsession performance changes are often reported (Mackworth, 1970). In the present study, however, no effect of the withinsession period was observed, presumably in part because the mode of presentation was abruptly altered between periods in the manner described. On the other hand, changes in performance between sessions were observed, but these are confounded with the order of presentation of the conditions $A, V$, and AV. A comparison between the first six and the final six sessions did reveal the presence of a slight practice effect [increased $p(H)$, but reduced $p(F A)$ and $R T]$, but this was similar for each mode of presentation and did not alter the statistical relations in the cross-modal comparisons on any score. For present purposes, which advised caution, the data are treated as stationary.

\section{RESULTS AND DISCUSSION}

\section{Overall Findings}

Table 1 summarizes the mean data over all subjects and sessions in terms of the seven measures of performance under the three experimental conditions. In Columns V to VIII of this table, the results of Wilcoxon $T$ comparisons between the three conditions are presented. The following results are clear from these comparisons:

(1) Mean percent detection under the AV condition exceeded that in both $A$ and V. Column VIII shows that this measure was also greater than the better of the unimodal conditions for each subject.

(2) False alarm rates in both $\mathrm{V}$ and $\mathrm{AV}$ were higher than in $A$, but no difference was evident between $\mathrm{V}$ and $\mathrm{AV}$ on this measure. The comparison in Column VIII is in this case that between false alarms in AV and the condition with the fewest false alarms for each subject.

(3) In terms of percent correct, A was superior to $\mathrm{V}$ but did not differ from AV. In general, however, $A V$ was superior to the better unimodal condition for each subject and was decidedly better than $\mathrm{V}$ alone.

(4) No difference was evident between the proportions of "signal" reports made in the $A$ and $V$ conditions, while significantly more reports were made in the AV condition than in either of the unimodal ones.

(5) The statistic $d^{\prime}$ was significantly higher under $A$ than under $\mathrm{V}$ conditions, and greater under AV than V. However, $d^{\prime}$ did not differ between $A V$ and $A$. Column VIII compares d' between AV and the better unimodal condition for each subject; this difference was also nonsignificant, which is not surprising, since A was the better unimodal condition for 17 out of the 18 subjects.

(6) A significant difference was evident between $A$ and $V$ conditions in terms of $\beta$, A showing the more conservative strategy. The results of comparisons between $\mathrm{AV}$ and the unimodal conditions contrast with the equivalent ones for "signal" reports; under AV conditions, the scores were not significantly different from those under $V$, while they were different from $A$.

(7) There was no appreciable difference in RT between $A$ and $V$ conditions, and each was inferior to AV on this measure. Dual-mode presentation did appear to have improved RT over both unimodal conditions, whichever was the faster, but this just failed to reach significance [Column VIII; $T=41$, $p$ (two-tailed) $=.054]$.

The results for both percent correct and d' are in agreement and merely confirm the consensus of previous "vigilance" findings that dual-mode performance is at least as good as auditory performance and invariably superior to visual performance; that when a significant difference between auditory and visual display emerges, the auditory display is 
superior (Buckner \& McGrath, 1963; Colquhoun, 1975; Osborn et al, 1963). If this is taken to reflect a differential effect of the vigilance environment on the sensitivities of the two systems, then, in the study reported here, where no within-session trends were observed and $\mathrm{A}$ was consistently superior to $\mathrm{V}$, the effect must have occurred very rapidly, within the block duration of $20 \mathrm{~min}$.

In the present study, where discrimination between the same pair of signal durations was involved in both $\mathrm{A}$ and $\mathrm{V}$ conditions, so that the discriminations were cognitively equivalent (Dougherty et al., 1971), it is felt that there is a stronger case for regarding the auditory modality as truly superior to the visual one, than in those previous reports where an intensity discrimination was involved and where the superiority of the auditory modality may have resulted simply from a difference between the signal-to-noise ratios of the acoustic and visual stimuli, or from nonequivalence of the tasks. It is not unduly surprising, however, to find that the auditory system has the greater efficiency for temporal discrimination since it is effectively a time-based system, receptive to sounds which are themselves "intrinsically temporal events"' (Neisser, 1966).

Just as percent correct and $\mathrm{d}^{\prime}$ can be considered parallel measures of accuracy, so too can $\beta$ and the probability of making a "signal" report be considered equivalent indices of the subject's criterion for responding. However, whereas the former pair of measures are in essential agreement according to the results in Table 1, the latter pair, indexing the criterion, are not. This apparent discrepancy may be resolved by noting that on the one hand, although $d^{\prime}$ and $\beta$ tended to be positively associated, this association failed to reach significance within any of the three conditions $\left(\mathrm{rho}_{\mathrm{a}}=.442\right.$; $\mathrm{rho}_{\mathrm{v}}=.110$; rho $_{\mathrm{av}}=.218 ; p>.05$ in each case), while, on the other hand, the percentage of "signal" reports was significantly, but negatively, related to percent correct within each condition $\left(\mathrm{rho}_{\mathrm{a}}=-.616, p<.02\right.$; rho $_{\mathrm{v}}=-.843, p<.01 ;$ rho $\left._{\mathrm{av}}=-.756, p<.01\right)$. In other words, the discrepancy may be viewed as merely reflecting the dependence of percent "signal" reports on observer accuracy (percent correct), while $\beta$ is independent of the accuracy, measured by $d^{\prime}$. The finding that $d^{\prime}$ and $\beta$ were not significantly correlated in the present study is of some importance if a signal detection theory argument (Green \& Swets, 1966 ) is to be maintained, in view of the criticism that these two measures, although theoretically independent, are not infrequently found to be related.

Also of some interest is the observation from the present data that if the typical subject based his decision to report on likelihood ratio (as signal detection theory prescribes), then he was far from optimal in the placement of his criterion (optimal $\beta$ for a "signal" probability of .05 would be 19.0 , assuming a symmetric payoff matrix; mean obtained $\beta$ was 4.26). If, on the other hand, he elected to adopt the (apparently) simpler strategy of matching the relative frequency of his "signal" reports to the relative frequency of "signal" presentations, then he seems to have fared rather well (probability of a "signal" was .05; mean probability of a "signal" report was .07). Such "probability matching" as an alternative rationale for setting decision criteria was advanced by Atkinson (1963) and has been observed subsequently in several psychophysical studies (Atkinson, Carterette, \& Kinchla, 1964; Creelman \& Donaldson, 1968; Kinchla \& Atkinson, 1964; Parks \& Kellicut, 1968; Kinchla, Note 2). In this context, it is perhaps worth noting that the percentage of "signal" reports was independent of $d$ ' (rho $=-.104, p>.10$ ). The implication of this is that one could use these empirical findings in support of a model which incorporated the probability matching strategy and in which the inferred decision process and the discrimination process would still be independent of each other, a theoretical nicety which is surely required of any alternative to signal detection theory.

\section{Discussion of Findings in Relation to the Models}

In the description of the models presented in the introduction, it will have been apparent to the reader that the cueing model, alone of the five, yielded predictions which were qualitative only, and not quantitative in nature. The validity of these predictions can therefore be readily ascertained by inspection of Table 1. Quite clearly, the results contained in rows $e, f$, and $g$ indicate substantial support for the model. Not only did the efficiency of the cued modality (assumed on the basis of these results to be auditory) remain unaltered $\left(\mathrm{d}^{\prime}\right.$ av was not significantly different from $\mathrm{d}^{\prime}{ }_{a}$, whereas the latter's superiority over $\mathrm{V}$ was maintained), but the dualmode criterion (at least as indexed by $\beta$ ) was predictably closer to that of $\mathrm{V}$ (the alerting mode) than of $\mathrm{A}$, while the latency of response was reduced as expected (response facilitation), since $\beta_{\mathrm{v}}$ was less than $\beta_{\mathrm{a}}$. On the basis of these compound tests of its predictions, the basic cueing model as described may be accepted.

In order that quantitative predictions can be made, thus making the model more directly comparable with the other four models, a "Mark II" version of the cueing model, with a more stringent assumption concerning the criterion shift, will be introduced. It will now be assumed that the cued modality (auditory) actually adopts the criterion of the alerting modality (visual) but retains its own level of efficiency. This implies that the inequality $4 \mathrm{a}$ becomes instead, the equation: 


$$
\beta_{\mathrm{av}}=\beta_{\mathrm{v}}
$$

and

$$
\beta_{\mathrm{av}} \neq \beta_{\mathrm{a}} \text {, when } \beta_{\mathrm{a}} \neq \beta_{\mathrm{v}}
$$

Although there seems little a priori justification for inserting this assumption, it is clear that it is acceptable for the present data as the results in row $f$ of Table 1 demonstrate. The advantages of its inclusion will become more readily apparent when the attempt is made to compare how well each model predicts the actual values of the dual-mode performance scores. Before progressing to that stage, however, it is worthwhile to consider further the implications of the Table 1 findings, since two of the remaining four models yield obvious qualitative predictions which may be checked against these results.

The statistical summation model carries the direct implication that both detections and false alarms should be greater under AV than in either A or V alone (see Equation 1). Columns VI and VII of Table 1 indicate that although this prediction is borne out in respect of percent detections, it is not supported by the data on false alarms, which evidenced no difference between the $\mathrm{AV}$ and the $\mathrm{V}$ condition. Similarly, row e of these two columns provides the information that although $\mathrm{d}^{\prime}{ }_{\text {av }}$ was significantly greater than $d^{\prime}{ }_{v}$, it was not greater than $\mathrm{d}^{\prime}{ }_{\mathrm{a}}$, a result which clearly conflicts with the qualitative prediction from the integration model (Equation 3) that the dual-mode efficiency level would be superior to both unimodal levels. These simple checks cast doubts on the validity of the models in question.

The Corcoran and Weening (1969) model and the phi model do not yield equivalently obvious qualitative predictions, and hence only tests of their quantitative predictions will be considered.

\section{Quantitative Predictions}

Table 2 tabulates, for each subject, the observed values of $\mathrm{d}^{\prime}$ in the AV condition, as well as the values predicted by each of the models. The reason for adopting $\mathrm{d}^{\prime}$ as the basis for this first comparison is that it is the only predicted value which is common to ail five models. The integration model predicts only d'; it makes no statement about criterion values, or about any of the more basic measures such as detection rate. The remaining four models permit either a direct (in the case of the modified cueing model) or an indirect (for the others) calculation of $d^{\prime}{ }^{\prime}$ av.

To assess the goodness-of-fit of the models, two measures have been used. The first of these is $\Sigma(\mathrm{O}-\mathrm{E})^{2}$, where $\mathrm{O}$ and $\mathrm{E}$ are, respectively, the observed and expected values of $\mathrm{d}^{\prime}$. This measure, which corresponds to the notion of mean square
Table 2

\begin{tabular}{|c|c|c|c|c|c|c|}
\hline \multirow[b]{2}{*}{ Subject } & \multirow[t]{2}{*}{ Observed } & \multicolumn{5}{|c|}{ Predicted } \\
\hline & & $\begin{array}{c}\text { Statis- } \\
\text { tical } \\
\text { Summa- } \\
\text { tion }\end{array}$ & $\begin{array}{c}\text { Corcoran } \\
\& \\
\text { Weening }\end{array}$ & $\begin{array}{c}\text { Integra- } \\
\text { tion }\end{array}$ & $\begin{array}{l}\text { Cue- } \\
\text { ing }\end{array}$ & Phi \\
\hline 1 & 2.31 & 2.40 & 2.82 & 2.79 & 2.43 & 2.37 \\
\hline 2 & 2.64 & 2.84 & 3.46 & 3.40 & 2.72 & 2.73 \\
\hline 3 & 2.04 & 2.25 & 2.78 & 2.67 & 2.00 & 2.20 \\
\hline 4 & 1.95 & 1.76 & 2.33 & 2.09 & 1.60 & 1.78 \\
\hline 5 & 1.30 & 1.34 & 1.65 & 1.58 & 1.27 & 1.40 \\
\hline 6 & 1.21 & 1.42 & 1.78 & 1.70 & 1.31 & 1.47 \\
\hline 7 & 1.49 & 1.69 & 2.11 & 2.04 & 1.61 & 1.71 \\
\hline 8 & 1.73 & 1.54 & 1.93 & 1.84 & 1.31 & 1.58 \\
\hline 9 & 2.09 & 2.02 & 2.48 & 2.41 & 2.01 & 2.02 \\
\hline 10 & 1.84 & 1.75 & 2.20 & 2.12 & 1.73 & 1.78 \\
\hline 11 & 2.44 & 2.45 & 3.02 & 2.91 & 2.27 & 2.30 \\
\hline 12 & 2.18 & 1.93 & 2.33 & 2.27 & 1.87 & 1.89 \\
\hline 13 & 2.26 & 2.24 & 2.73 & 2.59 & 2.95 & 2.12 \\
\hline 14 & 2.07 & 2.24 & 2.67 & 2.60 & 2.13 & 2.14 \\
\hline 15 & .62 & .85 & 1.05 & 1.03 & .51 & .95 \\
\hline 16 & 2.08 & 2.05 & 2.52 & 2.42 & 1.91 & 2.02 \\
\hline 17 & 1.75 & 1.56 & 1.96 & 1.87 & 1.39 & 1.60 \\
\hline 18 & 3.04 & 3.10 & 3.59 & 3.73 & 3.22 & 2.95 \\
\hline \multicolumn{2}{|c|}{$\Sigma(\mathrm{O}-\mathrm{E})^{2}$} & .45 & 4.44 & 3.43 & .79 & .49 \\
\hline \multicolumn{2}{|c|}{$\begin{array}{l}\text { Relative } \\
\text { Accuracy }\end{array}$} & 1.00 & 9.87 & 7.62 & 1.76 & 1.09 \\
\hline \multicolumn{2}{|c|}{$\operatorname{VAR}(\mathrm{O}-\mathrm{E})$} & .0244 & .0306 & .0385 & .0340 & .0275 \\
\hline \multicolumn{2}{|c|}{$\begin{array}{l}\text { Relative } \\
\text { Consistency }\end{array}$} & 1.00 & 1.25 & 1.58 & 1.39 & 1.12 \\
\hline \multicolumn{2}{|c|}{$\operatorname{Mean}(O-E)$} & .02 & .46 & .39 & .10 & .01 \\
\hline
\end{tabular}

Observed and Predicted Values of $d^{\prime}$ in the AV Condition

error used in defining the efficiency of an estimator of a parameter (see, for example, Atkinson, Bower, \& Crothers, 1965, pp. 375-376), indexes the accuracy of prediction; the model with the lowest value is the most accurate. The relative accuracy of any model may then be expressed as the ratio of its accuracy index to that of the most accurate model [i.e., $\Sigma(\mathrm{O}-\mathrm{E})_{\mathrm{j}}^{2} / \Sigma(\mathrm{O}-\mathrm{E})_{\min }^{2}$ ].

The second measure applied to the predictions is the variance of the $(\mathrm{O}-\mathrm{E})$ deviations. This measure may be thought of as reflecting the consistency of the goodness-of-fit of the models. Again, the model with the lowest variance is the most desirable; it is the most consistent and its variance has been used as the denominator in calculating the ratio which indexes the relative consistency of the predictions.

By inspection of Table 2, it is clear that the statistical summation model was the best predictor of $d^{\prime}$, both in terms of accuracy and consistency, although it was only marginally superior to the phi model. One would wish to reserve judgment on the cueing model since its relative accuracy score does not seem too high, but there seems little doubt that neither the Corcoran and Weening model nor the integration model fared well in this comparison. As it has already been pointed out that the integration model cannot be reconciled with the finding 
Table 3

Observed and Predicted Values of $\beta$ in the AV Condition

\begin{tabular}{|c|c|c|c|c|c|}
\hline \multirow[b]{2}{*}{ Subject } & \multirow[t]{2}{*}{ Observed } & \multicolumn{4}{|c|}{ Predicted } \\
\hline & & $\begin{array}{c}\text { Statistical } \\
\text { Summa- } \\
\text { tion }\end{array}$ & $\begin{array}{c}\text { Corcoran } \\
\& \\
\text { Weening }\end{array}$ & Cueing & Phi \\
\hline 1 & 4.43 & 2.32 & 46.33 & 5.00 & 4.83 \\
\hline 2 & 10.20 & 3.49 & 130.69 & 8.52 & 8.30 \\
\hline 3 & 4.43 & 1.62 & 21.92 & 3.61 & 3.58 \\
\hline 4 & 4.03 & 2.54 & 27.75 & 4.37 & 4.46 \\
\hline 5 & 2.90 & 1.85 & 10.16 & 2.71 & 2.94 \\
\hline 6 & 3.25 & 2.82 & 22.06 & 3.86 & 4.44 \\
\hline 7 & 4.15 & 2.88 & 29.56 & 4.18 & 4.95 \\
\hline 8 & 3.27 & 2.19 & 16.61 & 3.70 & 3.65 \\
\hline 9 & 4.84 & 2.58 & 35.55 & 4.18 & 4.95 \\
\hline 10 & 7.56 & 4.96 & 77.4 & 5.79 & 8.17 \\
\hline 11 & 6.09 & 2.06 & 39.84 & 4.53 & 4.89 \\
\hline 12 & 2.19 & 1.13 & 8.83 & 2.39 & 2.28 \\
\hline 13 & 1.84 & .82 & 7.43 & 2.37 & 1.93 \\
\hline 14 & 1.53 & .71 & 6.40 & 2.32 & 1.71 \\
\hline 15 & 1.83 & 1.56 & 4.71 & 2.32 & 2.19 \\
\hline 16 & 3.48 & 1.79 & 21.08 & 3.68 & 3.57 \\
\hline 17 & 5.04 & 3.22 & 32.09 & 4.57 & 5.28 \\
\hline 18 & 2.73 & .71 & 19.32 & 3.39 & 2.77 \\
\hline \multirow{5}{*}{\multicolumn{2}{|c|}{$\begin{array}{l}\Sigma(O-E)^{2} \\
\text { Relative Accuracy } \\
\text { VAR }(O-E) \\
\text { Relative Consistency } \\
\text { Mean }(O-E)\end{array}$}} & 104.93 & 26755.97 & 12.41 & 8.94 \\
\hline & & 11.73 & 2991.10 & 1.39 & 1.00 \\
\hline & & 2.15 & 763.61 & .67 & .49 \\
\hline & & 4.39 & 1558.39 & 1.37 & 1.00 \\
\hline & & 1.92 & 26.89 & .13 & .06 \\
\hline
\end{tabular}

that $\mathrm{d}^{\prime}{ }_{\mathrm{av}}$ was not greater than $\mathrm{d}^{\prime}{ }_{\mathrm{a}}$, the present additional evidence regarding the model's inaccuracy leaves little room for doubt about the inadequacy of the model, particularly in view of the limited scope of its predictions.

The second comparison was made in terms of $\beta$. Table 3 contains the results. The superiority of the phi model is obvious, but perhaps the most glaring aspect of these findings is the magnitude of the discrepancy in the Corcoran and Weening predictions. In previous reports on bimodal detection (Corcoran, 1971; Corcoran \& Weening, 1969), this model has been used exclusively as a predictor of detection rates, and these it seemed to handle rather well, especially when account was taken of the subject's option to ignore information from an insufficiently reliable second modality. On the one occasion where it has been used to predict scores which may be considered analogous to false alarms (namely the confusion errors in a recognition task), it is quite evident that the predictions tended to underestimate the scores (Corcoran \& Weening, 1969, p. 387). This is precisely what happened in the present case. The false-alarm rates, which were in any case typically low in this vigilance study, were underestimated by the model by a factor of more than six (mean observed false-alarm rate was $5.18 \%$, mean prediction was $0.81 \%$ ) as Table 5 reveals. This, in turn, was primarily responsible for the inflated values of the $\beta$ predictions shown in Table 3.

The present results also highlight an inconsistency in another feature of this model. The data on percent detections shown in Table 4 indicate that for 14 out of the 18 subjects, the wisest course of action (according to the model) would have been to ignore the visual information completely. This would certainly have improved the predictions on detection rate. Unfortunately, there exists no parallel case in which the subject would have been recommended to pursue the same strategy on the basis of the $A$ and $V$ falsealarm rates. The model, as it stands, can only resolve this conflict by assuming perfect auditory discrimination on the part of the observer so that he may elect to ignore the visual information on signal presentations, but to attend to the latter on nonsignal trials (which is, of course, illogical, if the auditory discrimination is perfect!). It is felt that the model's usefulness for data of the present kind terminates at this point.

The statistical summation model, which did so well in predicting $d^{\prime}$, is an inefficient predictor of $\beta$, according to the data in Table 3 . The low predicted values simply reflect the familiar evidence that the model incorporates a too liberal strategy, overpredicting both the detection rate and the false-alarm rate (Corcoran, 1971; Loveless et al., 1970). (See also Tables 4 and 5 of the present study.) What is

Table 4

Observed and Predicted Values of Percent Detections in the AV Condition

\begin{tabular}{|c|c|c|c|c|c|c|c|}
\hline \multirow[b]{2}{*}{$\begin{array}{l}\text { Sub- } \\
\text { ject }\end{array}$} & \multicolumn{3}{|c|}{ Observed } & \multicolumn{4}{|c|}{ Predicted } \\
\hline & $\mathbf{A}$ & $\mathbf{V}$ & AV & $\begin{array}{c}\text { Statis- } \\
\text { tical } \\
\text { Sum- } \\
\text { mation }\end{array}$ & $\begin{array}{c}\text { Corcoran } \\
\& \\
\text { Weening }\end{array}$ & $\begin{array}{l}\text { Cue- } \\
\text { ing }\end{array}$ & Phi \\
\hline 1 & 71.25 & 31.25 & 69.58 & 80.23 & 51.87 & 71.22 & 69.74 \\
\hline 2 & 68.33 & 48. & & & 62. & 71 & \\
\hline 3 & 58.75 & 56.25 & & 5 & 61. & & 6 \\
\hline 4 & 45.42 & 33.3 & 60.4 & 63.61 & 39.75 & & 5 \\
\hline 5 & 42.08 & 27.92 & 43.3 & 58.25 & 28.19 & 44. & 8 \\
\hline 6 & 33.33 & 23.75 & 35.42 & 49.16 & 19.80 & 34. & 3 \\
\hline 7 & 41.25 & 30.00 & 41.6 & 58.88 & 29.04 & 46. & 47.5 \\
\hline 8 & 38.75 & 35.42 & 57.0 & 60.44 & 31.06 & 37. & 48. \\
\hline 9 & 55.42 & 34.17 & 61.2 & 70.65 & 42.22 & 61. & 58. \\
\hline 10 & 35.00 & 20.42 & 49.92 & 48.27 & 18.83 & 44. & \\
\hline 11 & 62.08 & 53.33 & 68.33 & 82.30 & 61.47 & 67.9 & 67. \\
\hline 12 & 64.12 & 48.33 & 76.6 & 81.46 & 59.29 & 67.8 & 69. \\
\hline 13 & 68.75 & 63.75 & 80.42 & 88.67 & 73.51 & 71.6 & 77.5 \\
\hline 14 & 76.25 & 57.08 & 79.5 & 89.81 & 74.04 & 75.08 & \\
\hline 15 & 21.67 & 30.83 & 25.4 & 45.82 & 12.08 & 44.14 & \\
\hline 16 & 58.33 & 44.58 & 67.0 & 76.91 & 52.18 & & \\
\hline 17 & 32.08 & 27.92 & 47. & 51.04 & 21.60 & 35.70 & 40.56 \\
\hline 18 & 87.50 & 61.25 & 88.33 & 95.16 & 83.45 & 89.13 & 87.10 \\
\hline
\end{tabular}

Accuracy index:

$\Sigma(\mathrm{O}-\mathrm{E})^{2}$

Relative accuracy

Consistency index:

$\operatorname{VAR}(\mathbf{O}-\mathrm{E})$

$2626.5 \quad 4448.2 \quad 1307.0 \quad 567.1$

Relative consistency

$\begin{array}{llll}31.39 & 59.55 & 72.77 & 31.33\end{array}$

Mean $(O-E)$

$\begin{array}{llll}1.00 & 1.90 & 2.32 & 1.00\end{array}$

$10.70 \quad 13.70$

.40 
rather interesting to the present authors, and has not been pointed out in any previous reports, is the unexpected success of the model in predicting $\mathrm{d}^{\prime}$. It may of course be mere coincidence, applying to these data only, but it does seem an issue worth pursuing, particularly in view of the implicit suggestion that the psychological reality of the difference between the statistical summation and the phi models merely corresponds to a criterion shift.

In general, there can be little doubt but that the modified cueing model and the phi model offer the best value as predictors of dual-mode performance in the present study, with the phi model being the superior of the two. It was seen previously that the qualitative predictions of the earlier statement of the cueing model accorded well with the data. The modifications suggested in the Mark II version were stated to be somewhat suspect and one would not perhaps wish to extend them beyond the province of the data in hand, even though the results do seem in line with expectations in the presence of a strong cueing effect. But what if the cueing were relatively weak? The quantitative predictions would then have provided a rather poor fit to the data. Without introducing circularity to the argument, there seems no obvious way in which one could

Table 5

Observed and Predicted Values of Percent False Alarms in the AV Condition

\begin{tabular}{|c|c|c|c|c|c|c|c|}
\hline \multirow[b]{2}{*}{$\begin{array}{l}\text { Sub- } \\
\text { ject }\end{array}$} & \multicolumn{3}{|c|}{ Observed } & \multicolumn{4}{|c|}{ Predicted } \\
\hline & $\mathbf{A}$ & V & AV & $\begin{array}{c}\text { Statis- } \\
\text { tical } \\
\text { Sum- } \\
\text { mation }\end{array}$ & $\begin{array}{c}\text { Corcoran } \\
\& \\
\text { Weening }\end{array}$ & $\begin{array}{l}\text { Cue- } \\
\text { ing }\end{array}$ & Phi \\
\hline 1 & 3.05 & 3.16 & 3.60 & 6.11 & .28 & 2.96 & 3.20 \\
\hline 2 & 1.25 & 1.91 & 1.4 & 3.14 & .08 & 1.57 & 1.57 \\
\hline 3 & 3.75 & 5.39 & 3.99 & 8.94 & .61 & 4.90 & 4.60 \\
\hline 4 & 4.30 & 3.84 & 4.56 & 7.97 & .48 & 4.34 & 4.20 \\
\hline 5 & 7.08 & 6.29 & 7.13 & 12.92 & 1.28 & 7.72 & 7.10 \\
\hline 6 & 4.06 & 3.64 & 5.75 & 7.55 & .43 & 4.44 & 4.00 \\
\hline 7 & 3.39 & 3.86 & 4.41 & 7.12 & .39 & 4.66 & 3.70 \\
\hline 8 & 5.46 & 4.89 & 6.07 & 10.08 & .78 & 5.03 & 5.40 \\
\hline 9 & 3.05 & 4.06 & 3.57 & 6.99 & .37 & 4.28 & 3.60 \\
\hline 10 & 1.69 & 2.20 & 2.17 & 3.68 & .10 & 3.04 & 1.90 \\
\hline 11 & 2.48 & 4.08 & 2.52 & 6.46 & .32 & 3.55 & 3.30 \\
\hline 12 & 6.56 & 9.30 & 7.35 & 12.25 & 1.80 & 7.99 & 8.40 \\
\hline 13 & 7.15 & 8.71 & 8.09 & 15.24 & 1.79 & 7.64 & 8.50 \\
\hline 14 & 7.78 & 9.47 & 10.72 & 16.51 & 2.11 & 7.26 & 9.30 \\
\hline 15 & 9.78 & 8.16 & 10.00 & 17.14 & 2.27 & 14.74 & 9.70 \\
\hline 16 & 4.43 & 5.26 & 5.04 & 9.46 & .68 & 4.71 & 5.10 \\
\hline 17 & 3.14 & 3.27 & 3.58 & 6.31 & .30 & 3.68 & 3.30 \\
\hline 18 & 1.93 & 5.61 & 3.20 & 7.4 & .44 & 2.2 & \\
\hline \multicolumn{4}{|c|}{$\begin{array}{l}\text { Accuracy index: } \\
\Sigma(O-E)^{2}\end{array}$} & 378.07 & 408.63 & 42.86 & 8.92 \\
\hline \multicolumn{4}{|c|}{ Relative accuracy } & 42.40 & 45.83 & 4.81 & 1.00 \\
\hline \multicolumn{4}{|c|}{$\begin{array}{l}\text { Consistency index: } \\
\text { VAR }(O-E)\end{array}$} & 3.57 & 3.61 & 2.37 & .47 \\
\hline \multicolumn{4}{|c|}{ Relative consistency } & 7.67 & $7.75^{-}$ & 5.09 & 1.00 \\
\hline \multicolumn{4}{|c|}{$\operatorname{Mean}(\mathrm{O}-\mathrm{E})$} & 4.18 & 4.37 & .11 & .16 \\
\hline
\end{tabular}

Table 6

Correlation Across Conditions Between the Seven Measures of Performance

\begin{tabular}{lccc}
\hline \multicolumn{1}{c}{ Measures } & $\begin{array}{c}\text { Auditory } \\
\text { With } \\
\text { Visual }\end{array}$ & $\begin{array}{c}\text { Auditory } \\
\text { With } \\
\text { Audio- } \\
\text { Visual }\end{array}$ & $\begin{array}{c}\text { Visual } \\
\text { With } \\
\text { Audio- } \\
\text { Visual }\end{array}$ \\
\hline Percent Detection & .803 & .939 & .846 \\
Percent False Alarms & .756 & .804 & .962 \\
Percent Correct & .804 & .961 & .835 \\
Percent "Signal" Reports & .856 & .948 & .847 \\
d' & .870 & .923 & .860 \\
$\beta$ & .885 & .944 & .922 \\
RT & .893 & .963 & .817 \\
\hline
\end{tabular}

Table 7

Values of the Phi Correlation Coefficient Derived from the Detection Rate Data

\begin{tabular}{cccc}
\hline Subject & $\phi$ & Subject & $\phi$ \\
\hline 1 & .508 & 10 & .278 \\
2 & .718 & 11 & .477 \\
3 & .848 & 12 & .200 \\
4 & .136 & 13 & .370 \\
5 & .674 & 14 & .486 \\
6 & .685 & 15 & .985 \\
7 & .762 & 16 & .401 \\
8 & .145 & 17 & .149 \\
9 & .399 & 18 & .424 \\
\hline
\end{tabular}

Note-Mean $\phi=.480 ;$ this does not differ significantly from the expected value of $.50(t=.334)$. Var $\phi=.0608$.

modify the quantitative predictions so as to reflect gradations in the strength of the cueing effect. Despite these drawbacks, however, the earlier statement of the model retains a certain attractiveness, particularly in that it does attempt to describe the underlying processing which might be involved in dual-mode detection. In addition, it is the only one of the five models which directly predicts the observed response facilitation.

Compared with the cueing model, the phi model is rather crude and does little more than describe the data (although admittedly it does this very well), providing little insight into the nature of the underlying processing involved. What it does hint at, though, is that the auditory and the visual systems are not independent. While the goodness-of-fit of the model merely suggests that its assumption of an association between the systems may be valid, the correlations which are presented in Tables 6 and 7 and which are all significant $(p<.01)$ bear more directly on this issue.

In terms of the extent to which the data unambiguously indicate the presence of an association between the auditory and visual systems, the evidence in Table 6 is perhaps the weaker of the two sets. These correlations could merely imply, for example, that the subject who is fast, efficient, but, say, liberal (low criterion) in the A condition tends also to be fast, efficient, and liberal in the $\mathrm{V}$ and $\mathrm{AV}$ 
modes; that the subject who is slow, inefficient, and strict (high criterion) in the $\mathrm{V}$ mode, will probably manifest similar behavior in the other two conditions. The high correlations might reflect individual differences of a sort comparable to those between the athletic type and the person who is not athletically endowed. The former is good at running, jumping, and climbing; the latter is poor at all three. Analogously, one might infer that individuals differ in their ability to monitor and that the ability is independent of the particular mode in which the monitoring is conducted. A summary and discussion of previous reports which support this individual differences interpretation is presented by Colquhoun (1975). That evidence, as well as the present data, confirms the view of Gunn and Loeb (1967) that there is a common factor influencing sensitivity in detecting auditory and visual signals (as is revealed by high cross-modal correlations in $\left.d^{\prime}\right)$. Despite the present data, however, there appears to be no similar consensus regarding significant crossmodal correlations in $\beta$.

While the cross-modal correlations in Table 6 may be construed as implying that the individuals vary in the extent to which the whole system is tuned for discrimination, rather than that the auditory and visual subsystems are interdependent, the significant values of phi in Table 7 imply that there actually is some link between the subsystems. The interpretation of phi made here is the direct, statistical one. It reduces the complexities of the present bimodal detection paradigm to the relative simplicity of an urn-occupancy problem: how many urns contain both a red and a black ball if red balls are distributed over half the urns, one ball to each urn, and black balls distributed over three-quarters of the urns, again one to each? For this problem, a significant value of phi would indicate that there are more cases of dual occupancy than would be expected on chance grounds; it would also mean that fewer urns are occupied. The first point is equivalent to the consideration; how often are the auditory and visual systems in agreement on the outcome of a given trial? The significant phi values indicate that mutual agreement between the systems occurs more frequently than would be expected if the systems were independent (this assumes, of course, that for each of the systems the unimodal and bimodal performances are identical. Although this assumption has not been tested in the case of duration discrimination, Eijkman and Vendrick (1965) have shown that it holds for an intensity discrimination task). The second point, a corollary to the first, can be equated with failure to meet the performance-parity criterion (Garner \& Morton, 1969): there are fewer hits and fewer correct decisions in the dual-mode condition than one would expect from the combination of two independent systems. The evidence therefore is taken to support the notion that the systems are not independent. Acceptance of this view not only rules out those models which assume independence, but also helps to explain their failure of prediction. Thus, for example, the integration model and the statistical summation model must inevitably suffer, because they implicitly assume that performance parity will prevail. Similarly, the Corcoran and Weening model fails to meet acceptance, not necessarily because of the inconsistencies which were pointed out earlier, but due to the assumption of independence.

This finding, that the systems are not independent, does not itself give direct support for the specific phi model, which was stated in the introduction, but it is clear that the mean value of the observed phi shown in Table 7 is sufficiently close to the expected value, which appears as a parameter in the model, to justify the predictive equation as given.

As stated previously, the phi model is rather crude, offering little more than a description of input-output functions, and to go beyond this is to enter the realms of speculation. Nevertheless, it does not seem unreasonable to consider the possibility that the observed interdependence of the auditory and visual systems is the consequence of there being a central comparator or decision-maker which is shared in common by the two systems. The decisionmaker's role, for example, might be just that: to establish the criterion or response bias which is then applied to the individual (in the case of the $A$ and $V$ conditions) or combined (for the AV condition) analogue inputs. Such a process could account for the observed lack of independence in the data. Alternatively, one could speculate that the two systems do not share any common process, but that they are both simultaneously subjected to the common influence of momentary fluctuations in the level of internal noise within the organism. This, too, would have the effect of producing correlated outputs from the systems. The latter speculation might then link up with an explanation for the cross-modal correlations: individuals differ in detection or monitoring ability because they have different levels of internal noise; fluctuations in these levels give rise to the impression that separate systems are associated, since they are affected simultaneously during bimodal presentation.

As was mentioned in the introductory section, this suggestion of cross-modal correlation at the analogue level has been considered previously. Of particular relevance is the study by Eijkman and Vendrik (1965), because they concluded that correlation between the internal noise in the auditory and visual systems exists for duration discrimination but not for intensity discrimination, in which case the success of the phi model in the present study would seem entirely predictable. But Eijkman and Vendrik's conclusions are open to question. 
The reported independence of the systems in intensity discrimination is based on data from only two subjects and is contradicted by Fidell's (1970) results, which indicate a consistently negative association between the systems, although his data are countered in turn by those of Loveless et al. (1970, pp. 176-177), which imply that the systems are positively associated at this analogue level. This lack of consistency in the findings suggests that the issue is still an open one, but one which would seem worthy of further pursuit.

For duration discrimination, Eijkman and Vendrik report almost perfect cross-modal correlation, but this rests on the critical, but untested, assumption that the sensory observation during bimodal presentation is the average of the separate observations in the auditory and visual channels (if the bimodal observation were the sum of the auditory and visual ones, their correlations would be negative, while if it were the root mean square of the unimodal observations, the correlations would be about zero, signifying independence). It would seem, then, that the present results are best regarded as corroborating Eijkman and Vendrik's conclusion (rather than being predicted by it) and that accounting for them remains open to speculation.

Despite the uncertainty about the possible factors contributing to its success, the phi model, with its relative simplicity of assumption, may nevertheless be accorded merit for its predictive value. It provides a useful means of answering the empirical question with which this paper began.

\section{REFERENCE NOTES}

1. Loveless, N. E. Signgl detection with simultaneous visual and auditory presentation. Air Ministry, F.P.R.C. Report No. 1027, 1957.

2. Kinchla, R. A. A comparison of sequential effects in detection and recognition. Experimental Psychology Series, Psychology Department. New York University. Technical Report No. 1, 1966.

\section{REFERENCES}

Atkinson, R. C. A variable sensitivity theory of signal detection. Psychological Review, 1963, 70, 91-106.

Atrinson, R. C., Bower, G. H., \& Crothers, E. J. An introduction to mathematical leaming theory. New York: Wiley, 1965.

Atkinson, R. C., Carterrette, E. C., \& Kinchla, R. A. The effect of information feedback upon psychophysical judgments. Psychonomic Science, 1964, 1, 83-84.

Baker, R. A., Ware, J. R., \& Sipowicz, R. R. Vigilance: A comparison in auditory, visual and combined audio-visual tasks. Canadian Journal of Psychology, 1962, 16, 192-198.

Bernstein, I. H. Can we see and hear at the same time? Some recent studies of intersensory facilitation of reaction time. In A. F. Sanders (Ed.), Attention and performance III. Acta Psychologica, 1970, 33, 21-35.

Bernstein, I. H., Rose, R., \& Ashe, V. Preparatory state effects in intersensory facilitation. Psychonomic Science, $1970,19,113-114$
Broadbent, D. E., \& Gregory, M. Vigilance considered as a statistical decision. British Journal of Psychology, 1963, 54, 309-323.

Brown, A. E., \& Hopkins, H. K. Interaction of auditory and visual sense modalities. Journal of Acoustical Society of America, 1967, 41, 1-6.

BUCKNER, D. N., \& MCGrath, J. J. A comparison of performances on single and dual sensory mode vigilance tasks. In D. N. Buckner \& J. J. McGrath (Eds.), Vigilance: a symposium. New York: McGraw-Hill, 1963. Pp. 53-69.

Colquhoun, W. P. Evaluation of auditory, visual, and dualmode displays for prolonged sonar monitoring in repeated sessions. Human Factors, 1975, 17, 425-437.

Colquhoun, W. P., \& Baddeley, A. D. Influence of signal probability during pretraining on vigilance decrement. Journal of Experimental Psychology, 1967, 73, 153-155.

Corcoran, D. W. J. Pattern recognition. Harmondsworth: Penguin Books, 1971.

Corcoran, D. W. J., \& WeEnING, D. L. On the combination of evidence from the eye and ear. Ergonomics, 1969, 12. 383-394.

Creelman, C. D., \& Donaldson, W. ROC curves for discrimination of linear extent. Joumal of Experimental Psychology, 1968, 77, 514-516.

DAVEnPort, W. G. Vigilance for simultaneous auditory and cutaneous signals. Canadian Journal of Psychology, 1969. 23, 93-100.

Dougherty, W. G., Jones, G. R., \& Engel, G. R. Sensory integration of auditory and visual information. Canadian Journal of Psychology, 1971, 25, 476-485.

Eijkman, E., \& Vendruk, A. J. H. Can a sensory system be specified by its internal noise? Journal of the Acoustical Society of America, 1965, 37, 1102-1109.

Fidell, S. Sensory function in multimodal signal detection. Journal of the Acoustical Society of America, 1970, 47. 1009-1015.

Freeman, P. R. Table of $d^{*}$ and $\beta$. Cambridge: University Press, 1973.

Garner, W. R., \& Morton, J. Perceptual independence: Definitions, models, and experimental paradigms. Psychological Bulletin, 1969, 72, 233-259.

GREEN, D. M., \& SWETS. J. A. Signal detection theory and psychophysics. New York: Wiley, 1966.

Gunn, W. J., \& LoEB, M. Correlation of performance in detecting visual and auditory signals. American Journal of Psychology, 1967, 80, 236-242.

HERShenson, M. Reaction time as a measure of intersensory facilitation. Journal of Experimental Psychology, 1962, 63. $289-293$.

Howarth, C. I., \& Treisman, M. The effects of warning interval on the electric phosphere to auditory thresholds. Quarterly Joumal of Experimental Psychology, 1958, 10, 130-141.

Kinchla, R. A., \& Atkinson, R. C. The effects of false information feedback upon psychophysical judgments. Psychonomic Science, 1964, 1, 317-318.

KonfEld, D. L. Effects of the intensity of auditory and visual ready signais on simple reaction time. Joumal of Experimental Psychology, 1969, 82, 88-95.

Loveless, N. E., Brebner, J., \& Hamilton, P. Bisensory presentation of information. Psychological Bulletin, 1970. 73, 161-199.

MACKWORTH, J. F. Vigilance and attention. Harmondsworth: Penguin Books, 1970.

MoRRELL, L. K. Temporal characteristics of sensory interaction in choice reaction times. Journal of Experimental Psychology. 1968, 77, 14-18.

NeISSER, U. Cognitive psychology. New York: AppletonCentury-Crofts, 1966.

Nickerson, R. S. Intersensory facilitation of reaction time: Energy summation or preparation enhancement. Psycho- 
logical Review, 1973, 80, 489-509.

Osborn, W. C., Sheldon, R. W., \& Baker, R. A. Vigilance performance under conditions of redundant and nonredundant signal presentation. Joumal of Applied Psychology, $1963,47,130-134$.

Parks, T. E., \& Kellicutr, M. H. The probability-matching decision rule in the visual discrimination of order. Perception \& Psychophysics, 1968, 3, 356-360.

Pollack, I. Interaction between auditory and visual information sources in word recognition. Language and Speech, $1964,7,76-83$.

RAAB, D. H. Statistical facilitation of single reaction times. Transactions of the New York Academy of Sciences, 1961, Session II, 24, No. 5.

TODD, J. W. Reaction to multiple stimuli. Archives of Psychology, New York, 1912, 3, 1-65.

Treisman, M. The effect of one stimulus on the threshold for another: an application of signal detectability theory. British Journal of Mathematical and Statistical Psychology, 1964, 17, 15-35.
Tulving, E., Mandler, G., \& Baumal, R. Interaction of two sources of information in tachistoscopic word recognition. Canadian Journal of Psychology, 1964, 18, 62-71.

Tyler, D. M., WaAg., W. L., \& Halcomb, C. G. Monitoring performance across sense modes: An individual difference approach. Human Factors, 1972, 14, 539-547.

\section{NOTE}

1. In the case of word-recognition studies, the model actually underpredicts (Corcoran, 1971). A variant of this theory has been suggested for bimodal RT data (Raab, 1961; see also Hershenson, 1962; Nickerson, 1973).

(Received for publication September 15, 1975; revision received April 2, 1976.) 